\title{
Specialty Supplements and Prostate Cancer Risk in the VITamins And Lifestyle (VITAL) Cohort
}

\author{
Theodore M. Brasky, \\ Cancer Prevention Program, Fred Hutchinson Cancer Research Center, Seattle, WA, \\ Department of Epidemiology, University of Washington, Seattle, WA
}

Alan R. Kristal,

Cancer Prevention Program, Fred Hutchinson Cancer Research Center, Seattle, WA, Department of Epidemiology, University of Washington, Seattle, WA

Sandi L. Navarro,

Cancer Prevention Program, Fred Hutchinson Cancer Research Center, Seattle, WA, Department of Epidemiology, University of Washington, Seattle, WA

\author{
Johanna W. Lampe, \\ Cancer Prevention Program, Fred Hutchinson Cancer Research Center, Seattle, WA, \\ Department of Epidemiology, University of Washington, Seattle, WA
}

Ruth E. Patterson,

Department of Family and Preventive Medicine, University of California - San Diego, San Diego, CA

\author{
Ulrike Peters, and \\ Cancer Prevention Program, Fred Hutchinson Cancer Research Center, Seattle, WA, \\ Department of Epidemiology, University of Washington, Seattle, WA

\section{Emily White} \\ Cancer Prevention Program, Fred Hutchinson Cancer Research Center, Seattle, WA, \\ Department of Epidemiology, University of Washington, Seattle, WA
}

\begin{abstract}
Although there is evidence from studies of prostate cancer cell lines and rodent models that several supplements may have anti-inflammatory, anti-oxidant, or other anti-cancer properties, few epidemiologic studies have examined the association between non-vitamin, non-mineral, "specialty" supplement use and prostate cancer risk. Participants, 50-76 years, were 35,239 male members of the VITamins And Lifestyle (VITAL) cohort who were residents of western Washington State, and who completed an extensive baseline questionnaire in 2000-2002. Participants responded about their frequency (days/week) and duration (years) of specialty supplement uses. 1,602 incident invasive prostate cancers were obtained from the Surveillance, Epidemiology, and End Results registry. Multivariate-adjusted hazards ratios (HR) and 95\% confidence intervals $(95 \% \mathrm{CI}$ ) were estimated by Cox proportional hazards models. Any use of grapeseed supplements was associated with a $41 \%$ (HR 0.59, 95\% CI: 0.40-0.86) reduced risk of total prostate cancer. There were no associations for use of chondroitin, co-enzyme Q10, fish oil, garlic, ginkgo biloba, ginseng, glucosamine, or saw palmetto. Grapeseed may be a potential chemopreventive agent, however as current evidence is limited, it should not yet be promoted for prevention of prostate cancer.
\end{abstract}

Corresponding Author: Theodore M. Brasky, Fred Hutchinson Cancer Research Center, 1100 Fairview Ave. N., M4-B402, Seattle, WA 98109-1024, tbrasky@fhcrc.org. 


\section{Keywords}

Botanical; Epidemiologic; Nutraceutical; Prostate; Supplements

\section{Introduction}

Dietary supplement use has increased in the United States in recent decades, including substantial increases in use of non-vitamin, non-mineral supplements (hereafter, "specialty supplements") (1-3). Several specialty supplements have in vitro and in vivo anti-cancer properties, however relatively little is known regarding the long-term effects of these compounds on cancer development. For example, glucosamine, chondroitin, and fish oil have anti-inflammatory properties (4-7); and other supplements, including coenzyme Q10, garlic extract, ginseng, and grapeseed have anti-proliferative and other anti-cancer properties (8-13). These and others (e.g., saw palmetto) have biological activity in prostate cells (1424). However, there are almost no human studies of these supplements and prostate cancer risk. In a previous analysis, we found no association of regular saw palmetto use with prostate cancer risk in the VITamins And Lifestyle (VITAL) cohort after 2 years of followup (25).

We report here on the associations between use of nine commonly used specialty supplements and prostate cancer risk after 6 years of follow-up, among men in the VITAL cohort in western Washington State. Many men use these supplements because they believe that they have cancer-preventive properties; the results presented here may better inform these decisions.

\section{Materials and Methods}

\section{Study population}

Participants were male members of the VITAL cohort, a study designed to investigate the associations of the use of vitamin, mineral, and specialty supplements with cancer risk. Detailed methods have been previously reported (26). Men and women, aged 50-76 years, who were living in the 13-county region of western Washington State covered by the Surveillance, Epidemiology, and End Results (SEER) cancer registry were eligible to participate. Between 2000 and 2002, we mailed baseline questionnaires to 195,465 men, followed by a post-card reminder after 2 weeks. Of these, 37,382 (19.1\%) were returned and deemed eligible. This study was approved by the Institutional Review Board of the Fred Hutchinson Cancer Research Center.

Men who reported a history of prostate cancer $(n=2,013)$ or for those that did not report cancer history at baseline $(\mathrm{n}=128)$ were excluded. We additionally excluded men who were diagnosed with high-grade prostatic intraepithelial neoplasia after baseline $(n=2)$. After exclusions, there were 35,239 men available for study.

\section{Data collection}

The baseline questionnaire included a detailed assessment of specialty supplement use during the 10-year period prior to baseline, in addition to use of vitamin and mineral supplements. We inquired about current and past regular use ( $\geq 1$ day/week for $\geq 1$ year) of 18 specialty supplements. Nine of the most commonly used supplements are included in this analysis: chondroitin, co-enzyme Q10, fish oil, garlic pills, ginkgo biloba, ginseng, grapeseed, glucosamine, and saw palmetto. Questions included frequency of use (days/ week) and duration of use (years) over the previous 10 years. Because information on the 
potency of many specialty supplements is not available, we did not collect information on dose. Multivitamin use was also assessed, including the composition of multivitamin pills used. Some types of multivitamins, in particular those marketed for "men's health" contain "specialty" ingredients such as saw palmetto. However, the specialty supplements included in multivitamin formulations are typically in doses far less than those in individual supplements.

We did not evaluate the validity and reliability of our assessment of reported specialty supplement use. However, the accuracy of assessing 17 vitamin and mineral supplements in VITAL has been previously reported in a 3-month test-retest reliability sub-study of 220 randomly selected participants (27); intraclass-correlation coefficients ranged from 0.69 to 0.87 .

Participants also reported on known or suspected risk factors for prostate cancer and potential correlates of supplement use. These included height and weight; family history of prostate cancer; medical history, including prostate cancer screening, having a history of enlarged prostate or other chronic conditions; and lifestyle characteristics, including alcohol consumption. From data on height and weight, body mass index (BMI, $\mathrm{kg} / \mathrm{m}^{2}$ ) was computed. Participants who reported having had a heart attack, angina, angioplasty, or bypass surgery were considered to have a positive history of coronary artery disease.

\section{Case ascertainment}

Participants were followed for incident prostate cancer diagnoses from baseline to December 31, 2007; the median follow-up time was 6.1 years. We ascertained incident, invasive prostate cancers by linking the study cohort to the western Washington SEER cancer registry. All incident cancer cases except non-melanoma skin cancer diagnosed within the 13-county area of western Washington State are reported to SEER along with grade, stage, and other tumor characteristics. SEER ascertained cases through all area hospitals, offices of pathologists, oncologists, and radiotherapists, and from state death certificates. Extensive quality-control procedures ensure that registry data are accurate and complete. Linkage to SEER is based on ranking of the agreement between characteristics in common to VITAL and SEER, including name, social security number, date of birth, etc.; matches with high concordance were made automatically, while visual inspection was performed for matches in which some, but not all criteria matched. 1,602 eligible cases of prostate cancer were identified with diagnosis between baseline and December 2007.

Prior to 2004, SEER reported cancer grade as low, moderate, or high differentiation, based on two different algorithms using Gleason grade. From 2004 and onward, Gleason values of 1 to 5 were reported separately for primary and secondary Gleason patterns. As primary and secondary Gleason scores were not available for prostate cancers diagnosed prior to 2004, we conducted analyses of high and low-grade prostate cancers using incident data from 2004-2007 only. We classified high-grade tumors as those with Gleason scores 8-10 and 7 if the primary/secondary Gleason score was $4 / 3$. Tumors were considered to be low-grade if they had a Gleason score of 2-6 or 7 (if classified as 3/4). Between those years, there were 221 high-grade and 750 low-grade tumors available for study. In order to assess differences by stage, we additionally classified tumors as local $(n=1,362)$ or regional/distant $(n=229)$ for all years.

\section{Follow-up for censoring}

Excluding the $4.6 \%$ of the cohort with incident prostate cancer, the remaining participants were right-censored from the analysis at the earliest date of the following events: date of withdrawal from the study $(0.02 \%)$, date of death $(6.4 \%)$, date of emigration out of the 
SEER catchment region (5.6\%), or December 31, 2007, the most recent date that endpoints were ascertained through linkage to the SEER registry (83.4\%).

Deaths that occurred in the cohort were ascertained by linkage to the Washington state death file, using similar procedures to the SEER linkage. The National Change of Address System and active follow-up by telephone calls and mailings were used to identify men moving out of the SEER catchment area.

\section{Statistical analyses}

Chi-square tests were used to compare characteristics of VITAL participants by case status. Cox proportional hazards regression models with age as the time component were used to estimate prostate cancer hazards ratios (HR) and 95\% confidence intervals (95\% CI) associated with supplement use (SAS, v.9.1, 2002-2003, Cary, N.C.). All reported $P$-values are two sided $(\alpha=0.05) . P$-values for trend $(P$-trend) were calculated by treating categorical exposures as ordinal in proportional hazards models.

From information on frequency of regular supplement use ( $\geq 1$ week for $\geq 1$ year), each specialty supplement was categorized into user/non-user and by intake over the 10-years prior to baseline (non-user; low use [ $<4$ days/week or any use $<3$ years]; and high use [ $\geq 4$ days/week for $\geq 3$ years]). Intake from multivitamin sources was included in our estimates of 10 -year average use of garlic pills, ginkgo biloba, ginseng, grapeseed, and saw palmetto. Intake of supplements from multivitamins alone was classified as "low" 10-year average use, because the amounts of these supplements in multivitamins are generally much lower than those in individual supplements.

We selected a priori potential confounders, including known or suspected risk factors for prostate cancer or prostate cancer diagnosis. Multivariable models were adjusted for age (time variable), race (white, black, other), education ( $\leq$ high school graduate, some college, college or advanced degree), BMI $\left(<25,25-<30, \geq 30 \mathrm{~kg} / \mathrm{m}^{2}\right)$, prostate specific antigen (PSA) test in the past two years (yes/no), history of a benign prostate biopsy (yes/no), history of benign prostatic hyperplasia (BPH; yes/no), number of first-degree relatives with a history of prostate cancer (none, $1, \geq 2$ ), and diabetes (yes/no). We previously found that age, education, BMI, and a PSA test in the past two years were also associated with specialty supplement use (28).

We additionally adjusted multivariable models for a priori predictors of specialty supplement use, including multivitamin use (never, past, current) for all supplements and indications for use for specific supplements. Specifically, additional adjustments were made for personal histories of coronary artery disease (for analyses of fish oil, grapeseed); memory loss (for fish oil, ginkgo biloba); osteoarthritis (for glucosamine, chondroitin); or chronic joint pain (for glucosamine, chondroitin) (28). A positive history of BPH was an indication for saw palmetto use (28); it was adjusted for in all analyses because of the strong association between $\mathrm{BPH}$ and a diagnosis of prostate cancer.

To assess whether differences in etiology exist for supplement exposure in association with subgroups of prostate cancer, we stratified models on prostate tumor grade (low, high) and stage (local, regional/distant). Logistic regression models that were restricted to cases were used to calculate the $p$-value for heterogeneity ( $p$-heterogeneity) between subtypes of prostate cancer for associations with supplements. 


\section{Results}

Compared to non-cases, prostate cancer cases tended to be older at baseline, black race, consume more alcohol, take multivitamins, and report recent PSA testing, benign prostate biopsy, BPH, or a family history of prostate cancer (Table 1). Cases were less likely to be obese.

Multivariate-adjusted HR's and 95\% CI's for associations of specialty supplements with overall prostate cancer risk are given in Table 2. Men who used individual grapeseed supplements had a statistically significantly lower prostate cancer risk (HR 0.59, 95\% CI: $0.40-0.86$ ) compared with non-users. High 10-year average use was associated with a $62 \%$ reduction in prostate cancer risk (HR 0.38, 95\% CI: 0.19-0.76). However, low 10-year average use, primarily from use of multivitamins with a flavonoid component, was not associated with prostate cancer risk (HR 1.10,95\% CI: 0.89-1.37) and as indicated by the point estimates the association was not linear $(P$-trend $=0.17)$. Use of other specialty supplements was not significantly associated with prostate cancer risk overall.

Table 3 gives associations of supplement use with prostate cancer stratified by grade. Grapeseed use was inversely associated with both low-grade (HR 0.58, 95\% CI: $0.33-1.03$ ) and high-grade prostate cancer (HR 0.82, 95\% CI: 0.34-2.00) compared to non-users. Although the reduction in risk was stronger for low-grade tumors, neither finding achieved statistical significance and the $p$-heterogeneity was 0.58 . High 10-year average use was associated with a statistically significant reduction in low-grade (HR $0.21,95 \%$ CI: $0.05-$ 0.83 ), but not high-grade prostate cancer (HR 1.08, 95\% CI: 0.34-3.40) ( $p$ heterogeneity $=0.04$; data not shown), although these findings were based upon very small case numbers ( $n=3$ low-grade and $n=4$ high-grade cancers with high 10-year average use). There were no associations of the remaining supplements with prostate cancer grade. In addition, there were no differences in association for any supplement when prostate cancers were stratified by stage (data not shown).

\section{Discussion}

In this cohort of 35,239 men living in western Washington State, users of grapeseed supplements had a reduced risk of prostate cancer, particularly low-grade prostate cancer. The use of other supplements, including saw palmetto and ginkgo biloba, was not associated with risk of prostate cancer.

No previous study has investigated the association of grapeseed supplementation to prostate cancer risk. In terms of other cancers, we previously reported a non-significant risk reduction of colorectal cancer among grapeseed supplement users (HR 0.72, 95\% CI: 0.44 1.18 ) and no association of grapeseed use with risk of lung cancer (HR $0.97,95 \%$ CI: 0.68 1.38) in the VITAL cohort (29). In addition, a case-control study of squamous cell skin cancer found grapeseed users had a significantly decreased risk (OR $0.26,95 \%$ CI: 0.08 0.89) (30).

Grapeseed extract is marketed for its anti-oxidant, immune supportive, and cardio-protective properties (31). It contains a mixture of phenolic compounds including flavones, phenolic acids, and resveratrol $(31,32)$. Manufacturers recommend daily doses between 50mg and $600 \mathrm{mg}$ (33). Dietary grape products, particularly red wine, contain resveratrol and other phenols, and have been studied in association with prostate cancer. Among prospective studies, wine consumption has not been associated with prostate cancer risk (34-40). Hirvonen et al. (41), reported on the association of dietary flavonoids and risk of cancer in the Alpha-Tocopherol, Beta-Carotene Cancer Prevention (ATBC) Study, a large randomized, controlled trial in 27,110 male smokers in Finland. They reported no 
association between dietary flavonols and flavones and prostate cancer risk (RR 1.3, 95\% CI: 0.87-1.80) (41). Another prospective study in Finland also found no association of dietary flavonoids with prostate cancer risk (RR 1.14, 95\% CI: 0.70-1.84) (42). One explanation for the discrepancy between our finding and those from studies of diet is that users of grapeseed supplements may be exposed to higher doses of these phenolic compounds than they would from their regular diet. However, phenolic compounds in grapeseed are rapidly conjugated so it is possible that the association between grapeseed supplement use and prostate cancer is not due to a high phenolic intake $(43,44)$. Another explanation is that our finding is due to chance.

The anti-cancer properties of grapeseed or its constituents in prostate cancer cell lines and in rodent models of prostate cancer is an active area of research (45). In several prostate cancer cell lines, grapeseed extract or its constituents induce apoptosis and reduce proliferation (11, $18,46-54)$. These compounds have also been shown to have anti-inflammatory activity through inhibition of the nuclear factor kappa-B (NFKB) and cyclooxygenase pathways (11, $18,47,55)$. Grapeseed supplements contain flavonoids that reduce expression of IL-6 and partially inhibit NFkB translocation to the nucleus in some cell types (55). Several investigators have reported a reduction or delay of prostate tumor incidence when animals were fed grapeseed extract, resveratrol, or proanthocyanidins (19, 52, 56-58). Moreover, some components of grapeseed have been shown to reduce biomarkers of inflammation and oxidative stress in a recent randomized controlled trial in humans (59).

Only one epidemiologic study and one clinical trial have investigated use of specialty supplements in association with prostate cancer. We previously reported no association between use of saw palmetto, typically taken for BPH, and prostate cancer risk in this cohort (HR 0.95, 95\% CI: 0.74-1.23) (25); after an additional 4 years of follow-up, we continue to observe no association. Biggs et al. (60), reported results of a secondary analysis of the Ginkgo Evaluation of Memory (GEM) randomized trial. After 6 years of follow-up, the authors observed no significant difference in the risk of prostate cancer among men aged $>75$ years randomized to $120 \mathrm{mg}$ of ginkgo biloba extract taken twice daily compared to placebo (HR 0.71, 95\% CI: 0.43-1.17) (60). Similarly, we found no association of selfreported ginkgo biloba supplement use with prostate cancer risk.

This study has several limitations. Foremost, we did not ascertain information on postbaseline PSA screening, on PSA concentration, or a history of prostatitis. However, it is unlikely that residual confounding by PSA screening would explain the observed inverse association between grapeseed use and prostate cancer risk because supplement users are more likely to participate in cancer screening (26), and PSA screening would lead to greater, not lower prostate cancer detection. In addition, because we could not characterize prostate cancers by grade until 2004, we had small numbers of cases for that analysis. Another limitation is that we did not update information on exposures after baseline. Lastly, we had limited power to detect associations due to the low prevalence of some specialty supplements. This was particularly apparent when we stratified prostate cancers by grade. Similarly, because we examined 9 specialty supplements and made additional comparisons by tumor grade, it is possible that our findings could be due to chance.

This study has several strengths. It is the first prospective study designed specifically to investigate the association of specialty supplements with cancer risk. Supplement users were targeted at recruitment, to increase power to study the association of supplement use with cancer risk. In addition, information on supplement use was collected for the 10 years prior to baseline, providing long-term intake. We were able to adjust for many potential indications of supplement use, thereby reducing the likelihood of confounding by indication. 
Follow up on the VITAL cohort was $95 \%$ complete; therefore, bias due to differential loss is unlikely.

In summary, this is the first large prospective study of specialty supplement use and prostate cancer risk. Our findings do not support the use of most of the supplements studied for prostate cancer prevention. Our finding of a reduction in prostate cancer risk among users of grapeseed supplements is supported, at least in part, by experimental and animal studies of phenolic compounds. However, any public health recommendation for grapeseed would require replication of our findings in humans as well as further clarification of mechanisms of action.

\section{Acknowledgments}

This work is supported by grants R01-CA142545, R25-CA94880, and K05-CA154337 from the National Institutes of Health, National Cancer Institute

\section{References}

1. Eisenberg DM, Davis RB, Ettner SL, Appel S, Wilkey S, et al. Trends in alternative medicine use in the United States, 1990-1997: results of a follow-up national survey. Journal of the American Medical Association. 1998; 280:1569-1575. [PubMed: 9820257]

2. Kelly JP, Kaufman DW, Kelley K, Rosenberg L, Anderson TE, et al. Recent trends in use of herbal and other natural products. Arch. Intern. Med. 2005; 165:281-286. [PubMed: 15710790]

3. Tindle HA, Davis RB, Phillips RS, Eisenberg DM. Trends in use of complementary and alternative medicine by US adults: 1997-2002. Altern. Ther. Health Med. 2005; 11:42-49. [PubMed: 15712765]

4. Largo R, Alvarez-Soria MA, Diez-Ortego I, Calvo E, Sanchez-Pernaute O, et al. Glucosamine inhibits IL-1beta-induced NFkappaB activation in human osteoarthritic chondrocytes. Osteoarthritis Cartilage. 2003; 11:290-298. [PubMed: 12681956]

5. Zou L, Yang S, Champattanachai V, Hu S, Chaudry IH, et al. Glucosamine improves cardiac function following trauma-hemorrhage by increased protein O-GlcNAcylation and attenuation of NF-\{kappa\}B signaling. Am J Physiol Heart Circ Physiol. 2009; 296:H515-H523. [PubMed: 19098112]

6. Herrero-Beaumont G, Marcos ME, Sanchez-Pernaute O, Granados R, Ortega L, et al. Effect of chondroitin sulphate in a rabbit model of atherosclerosis aggravated by chronic arthritis. Br J Pharmacol. 2008; 154:843-851. [PubMed: 18536737]

7. Chapkin RS, Kim W, Lupton JR, McMurray DN. Dietary docosahexaenoic and eicosapentaenoic acid: emerging mediators of inflammation. Prostaglandins Leukot Essent Fatty Acids. 2009; 81:187-191. [PubMed: 19502020]

8. Sakano K, Takahashi M, Kitano M, Sugimura T, Wakabayashi K. Suppression of azoxymethaneinduced colonic premalignant lesion formation by coenzyme Q10 in rats. Asian Pac J Cancer Prev. 2006; 7:599-603. [PubMed: 17250435]

9. Tanaka S, Haruma K, Yoshihara M, Kajiyama G, Kira K, et al. Aged garlic extract has potential suppressive effect on colorectal adenomas in humans. J Nutr. 2006; 136:821S-826S. [PubMed: 16484573]

10. Amato P, Christophe S, Mellon PL. Estrogenic activity of herbs commonly used as remedies for menopausal symptoms. Menopause. 2002; 9:145-150. [PubMed: 11875334]

11. Jang M, Cai L, Udeani GO, Slowing KV, Thomas CF, et al. Cancer chemopreventive activity of resveratrol, a natural product derived from grapes. Science. 1997; 275:218-220. [PubMed: 8985016]

12. Boivin D, Blanchette M, Barrette S, Moghrabi A, Beliveau R. Inhibition of cancer cell proliferation and suppression of TNF-induced activation of NFkappaB by edible berry juice. Anticancer Res. 2007; 27:937-948. [PubMed: 17465224]

13. Panax ginseng. Monograph. Altern Med Rev. 2009; 14:172-176. [PubMed: 19594226] 
14. Quiles JL, Farquharson AJ, Ramirez-Tortosa MC, Grant I, Milne L. Coenzyme Q differentially modulates phospholipid hydroperoxide glutathione peroxidase gene expression and free radicals production in malignant and non-malignant prostate cells. Biofactors. 2003; 18:265-270. [PubMed: 14695942]

15. Arunkumar A, Vijayababu MR, Srinivasan N, Aruldhas MM, Arunakaran J, et al. Garlic compound, diallyl disulfide induces cell cycle arrest in prostate cancer cell line PC-3. Mol Cell Biochem. 2006; 288:107-113. [PubMed: 16691315]

16. Arunkumar A, Vijayababu MR, Venkataraman P, Senthilkumar K, Arunakaran J. Chemoprevention of rat prostate carcinogenesis by diallyl disulfide, an organosulfur compound of garlic. Biol Pharm Bull. 2006; 29:375-379. [PubMed: 16462049]

17. Kim HS, Lee EH, Ko SR, Choi KJ, Park JH, et al. Effects of ginsenosides Rg3 and Rh2 on the proliferation of prostate cancer cells. Arch Pharm Res. 2004; 27:429-435. [PubMed: 15180309]

18. Vayalil PK, Mittal A, Katiyar SK. Proanthocyanidins from grape seeds inhibit expression of matrix metalloproteinases in human prostate carcinoma cells, which is associated with the inhibition of activation of MAPK and NF kappa B. Carcinogenesis. 2004; 25:987-995. [PubMed: 14742313]

19. Raina K, Singh RP, Agarwal R, Agarwal C. Oral grape seed extract inhibits prostate tumor growth and progression in TRAMP mice. Cancer Res. 2007; 67:5976-5982. [PubMed: 17575168]

20. Yang Y, Ikezoe T, Zheng Z, Taguchi H, Koeffler HP, et al. Saw Palmetto induces growth arrest and apoptosis of androgen-dependent prostate cancer LNCaP cells via inactivation of STAT 3 and androgen receptor signaling. Int J Oncol. 2007; 31:593-600. [PubMed: 17671686]

21. Ferguson PJ, Kurowska E, Freeman DJ, Chambers AF, Koropatnick DJ. A flavonoid fraction from cranberry extract inhibits proliferation of human tumor cell lines. J Nutr. 2004; 134:1529-1535. [PubMed: 15173424]

22. Steiner C, Arnould S, Scalbert A, Manach C. Isoflavones and the prevention of breast and prostate cancer: new perspectives opened by nutrigenomics. Br J Nutr. 2008; 99 E Suppl 1:ES78-ES108. [PubMed: 18503737]

23. Chesnokov V, Sun C, Itakura K. Glucosamine suppresses proliferation of human prostate carcinoma DU145 cells through inhibition of STAT3 signaling. Cancer Cell Int. 2009; 9:25. [PubMed: 19744341]

24. Kobayashi N, Barnard RJ, Henning SM, Elashoff D, Reddy ST, et al. Effect of altering dietary omega-6/omega-3 fatty acid ratios on prostate cancer membrane composition, cyclooxygenase-2, and prostaglandin E2. Clin Cancer Res. 2006; 12:4662-4670. [PubMed: 16899616]

25. Bonnar-Pizzorno RM, Littman AJ, Kestin M, White E. Saw palmetto supplement use and prostate cancer risk. Nutr Cancer. 2006; 55:21-27. [PubMed: 16965237]

26. White E, Patterson RE, Kristal AR, Thornquist M, King I, et al. VITamins And Lifestyle cohort study: study design and characteristics of supplement users. Am J Epidemiol. 2004; 159:83-93. [PubMed: 14693663]

27. Satia-Abouta J, Patterson RE, King IB, Stratton KL, Shattuck AL, et al. Reliability and validity of self-report of vitamin and mineral supplement use in the vitamins and lifestyle study. Am J Epidemiol. 2003; 157:944-954. [PubMed: 12746248]

28. Gunther S, Patterson RE, Kristal AR, Stratton KL, White E. Demographic and health-related correlates of herbal and specialty supplement use. J Am Diet Assoc. 2004; 104:27-34. [PubMed: 14702580]

29. Satia JA, Littman A, Slatore CG, Galanko JA, White E. Associations of herbal and specialty supplements with lung and colorectal cancer risk in the VITamins and Lifestyle study. Cancer Epidemiol Biomarker Prev. 2009; 18:1419-1428.

30. Asgari MM, Chren MM, Warton EM, Friedman GD, White E. Supplement use and risk of cutaneous squamous cell carcinoma. J Am Acad Dermatol. 2010 (in press).

31. Nassiri-Asl M, Hosseinzadeh H. Review of the pharmacological effects of Vitis vinifera (Grape) and its bioactive compounds. Phytother Res. 2009; 23:1197-1204. [PubMed: 19140172]

32. Li X, Wu B, Wang L, Li S. Extractable amounts of trans-resveratrol in seed and berry skin in Vitis evaluated at the germplasm level. J Agric Food Chem. 2006; 54:8804-8811. [PubMed: 17090126] 
33. Crawford YG, Gauthier ML, Joubel A, Mantei K, Kozakiewicz K, et al. Histologically normal human mammary epithelia with silenced p16(INK4a) overexpress COX-2, promoting a premalignant program. Cancer Cell. 2004; 5:263-273. [PubMed: 15050918]

34. Albertsen K, Gronbaek M. Does amount or type of alcohol influence the risk of prostate cancer? Prostate. 2002; 52:297-304. [PubMed: 12210490]

35. Chao C, Haque R, Van Den Eeden SK, Caan BJ, Poon KY, et al. Red wine consumption and risk of prostate cancer: the California men's health study. Int J Cancer. 2010; 126:171-179. [PubMed: 19521962]

36. Ellison LF. Tea and other beverage consumption and prostate cancer risk: a Canadian retrospective cohort study. Eur J Cancer Prev. 2000; 9:125-130. [PubMed: 10830580]

37. Putnam SD, Cerhan JR, Parker AS, Bianchi GD, Wallace RB, et al. Lifestyle and anthropometric risk factors for prostate cancer in a cohort of Iowa men. Ann Epidemiol. 2000; 10:361-369. [PubMed: 10964002]

38. Schuurman AG, Goldbohm RA, van den Brandt PA. A prospective cohort study on consumption of alcoholic beverages in relation to prostate cancer incidence (The Netherlands). Cancer Causes Control. 1999; 10:597-605. [PubMed: 10616828]

39. Sutcliffe S, Giovannucci E, Leitzmann MF, Rimm EB, Stampfer MJ, et al. A prospective cohort study of red wine consumption and risk of prostate cancer. Int J Cancer. 2007; 120:1529-1535. [PubMed: 17211860]

40. Velicer CM, Kristal A, White E. Alcohol use and the risk of prostate cancer: results from the VITAL cohort study. Nutr Cancer. 2006; 56:50-56. [PubMed: 17176217]

41. Hirvonen T, Virtamo J, Korhonen P, Albanes D, Pietinen P. Flavonol and flavone intake and the risk of cancer in male smokers (Finland). Cancer Causes Control. 2001; 12:789-796. [PubMed: 11714106]

42. Mursu J, Nurmi T, Tuomainen TP, Salonen JT, Pukkala E, et al. Intake of flavonoids and risk of cancer in Finnish men: The Kuopio Ischaemic Heart Disease Risk Factor Study. Int J Cancer. 2008; 123:660-663. [PubMed: 18338754]

43. Walle T, Hsieh F, DeLegge MH, Oatis JE Jr, Walle UK. High absorption but very low bioavailability of oral resveratrol in humans. Drug Metab Dispos. 2004; 32:1377-1382. [PubMed: 15333514]

44. D'Archivio M, Filesi C, Di Benedetto R, Gargiulo R, Giovannini C, et al. Polyphenols, dietary sources and bioavailability. Ann Ist Super Sanita. 2007; 43:348-361. [PubMed: 18209268]

45. Services USDoHaH. Research Portfolio Online Reporting Tools (RePORT). 2010 Aug 1. Available from: http://projectreporter.nih.gov/reporter.cfm

46. Agarwal C, Agarwal R. Gallic acid causes inactivating phosphorylation of cdc25A/cdc25C-cdc2 via ATM-Chk2 activation, leading to cell cycle arrest, and induces apoptosis in human prostate carcinoma DU145 cells. Mol Cancer Ther. 2006; 5:3294-3302. [PubMed: 17172433]

47. Benitez DA, Hermoso MA, Pozo-Guisado E, Fernandez-Salguero PM, Castellon EA. Regulation of cell survival by resveratrol involves inhibition of NF kappa B-regulated gene expression in prostate cancer cells. Prostate. 2009; 69:1045-1054. [PubMed: 19301309]

48. Hudson TS, Hartle DK, Hursting SD, Nunez NP, Wang TT, et al. Inhibition of prostate cancer growth by muscadine grape skin extract and resveratrol through distinct mechanisms. Cancer Res. 2007; 67:8396-8405. [PubMed: 17804756]

49. Kaur M, Agarwal R, Agarwal C. Grape seed extract induces anoikis and caspase-mediated apoptosis in human prostate carcinoma LNCaP cells: possible role of ataxia telangiectasia mutated-p53 activation. Mol Cancer Ther. 2006; 5:1265-1274. [PubMed: 16731759]

50. Neuwirt H, Arias MC, Puhr M, Hobisch A, Culig Z. Oligomeric proanthocyanidin complexes (OPC) exert anti-proliferative and pro-apoptotic effects on prostate cancer cells. Prostate. 2008; 68:1647-1654. [PubMed: 18663730]

51. Shi WF, Leong M, Cho E, Farrell J, Chen HC, et al. Repressive effects of resveratrol on androgen receptor transcriptional activity. PLoS One. 2009; 4:e7398. [PubMed: 19816598]

52. Slusarz A, Shenouda NS, Sakla MS, Drenkhahn SK, Narula AS, et al. Common botanical compounds inhibit the hedgehog signaling pathway in prostate cancer. Cancer Res. 2010; 70:3382-3390. [PubMed: 20395211] 
53. Tyagi A, Agarwal R, Agarwal C. Grape seed extract inhibits EGF-induced and constitutively active mitogenic signaling but activates JNK in human prostate carcinoma DU145 cells: possible role in antiproliferation and apoptosis. Oncogene. 2003; 22:1302-1316. [PubMed: 12618755]

54. Veluri R, Singh RP, Liu Z, Thompson JA, Agarwal R, et al. Fractionation of grape seed extract and identification of gallic acid as one of the major active constituents causing growth inhibition and apoptotic death of DU145 human prostate carcinoma cells. Carcinogenesis. 2006; 27:1445-1453. [PubMed: 16474170]

55. Chacon MR, Ceperuelo-Mallafre V, Maymo-Masip E, Mateo-Sanz JM, Arola L, et al. Grape-seed procyanidins modulate inflammation on human differentiated adipocytes in vitro. Cytokine. 2009; 47:137-142. [PubMed: 19560935]

56. Harper CE, Cook LM, Patel BB, Wang J, Eltoum IA, et al. Genistein and resveratrol, alone and in combination, suppress prostate cancer in SV-40 tag rats. Prostate. 2009; 69:1668-1682. [PubMed: 19670229]

57. Seeni A, Takahashi S, Takeshita K, Tang M, Sugiura S, et al. Suppression of prostate cancer growth by resveratrol in the transgenic rat for adenocarcinoma of prostate (TRAP) model. Asian Pac J Cancer Prev. 2008; 9:7-14. [PubMed: 18439064]

58. Raina K, Rajamanickam S, Deep G, Singh M, Agarwal R, et al. Chemopreventive effects of oral gallic acid feeding on tumor growth and progression in TRAMP mice. Mol Cancer Ther. 2008; 7:1258-1267. [PubMed: 18445658]

59. Ghanim H, Sia CL, Abuaysheh S, Korzeniewski K, Patnaik P, et al. An Antiinflammatory and Reactive Oxygen Species Suppressive Effects of an Extract of Polygonum Cuspidatum Containing Resveratrol. J Clin Endocrinol Metab. 2010

60. Biggs ML, Sorkin BC, Nahin RL, Kuller LH, Fitzpatrick AL. Ginkgo biloba and risk of cancer: Secondary Analysis of the Ginkgo Evaluation of Memory (GEM) Study. Pharmacoepidemiol Drug Saf. 2010 (In Press). 


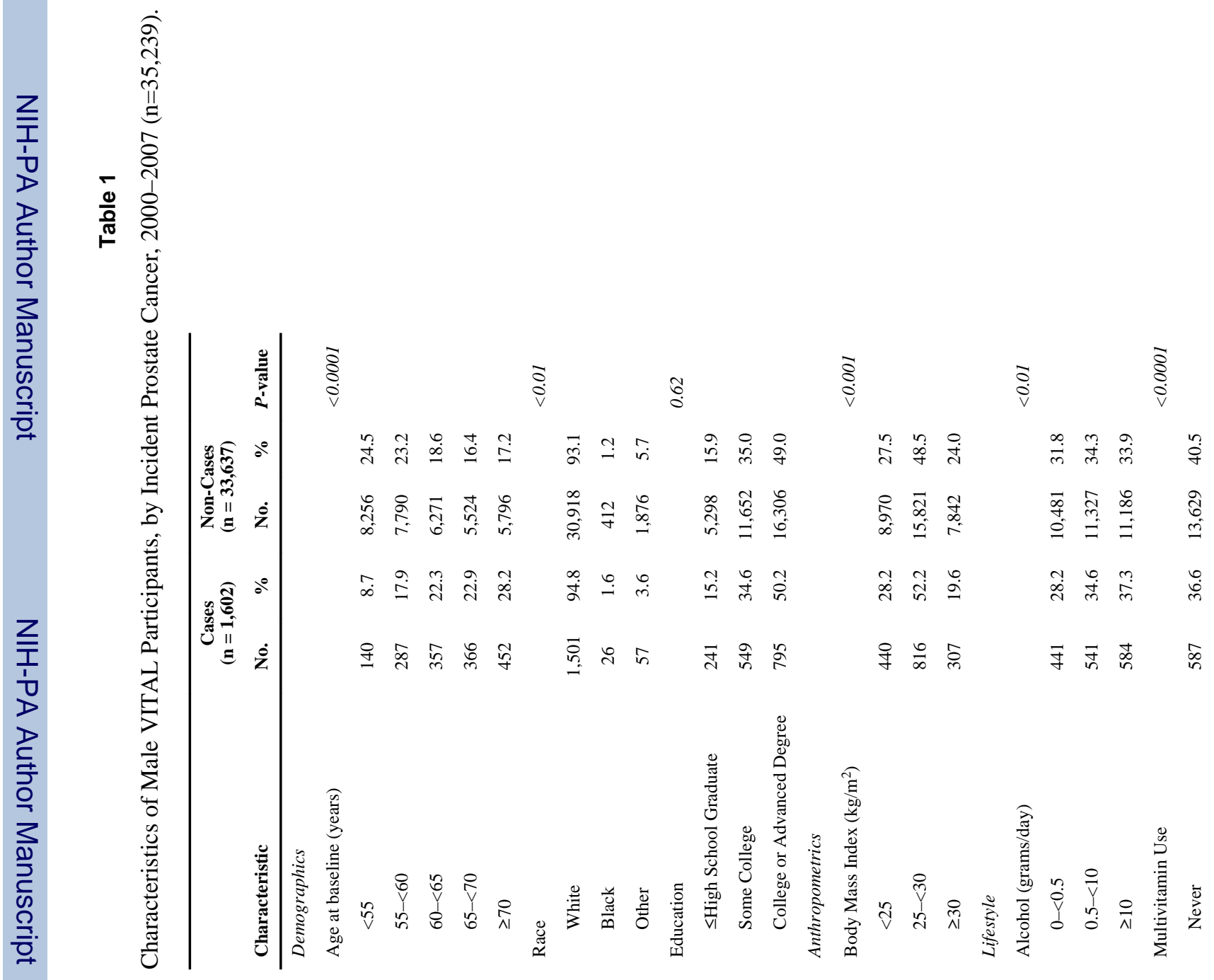




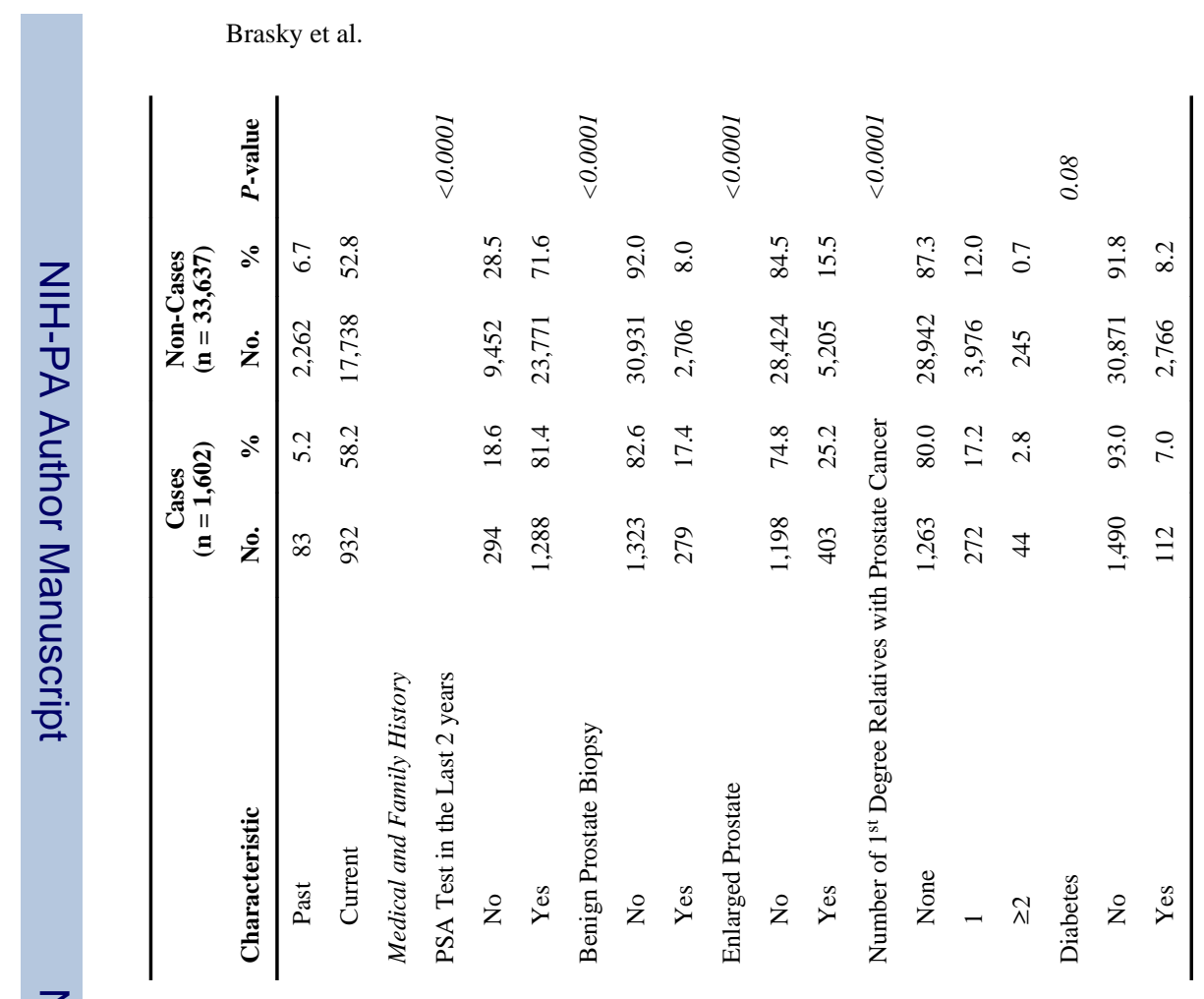

Page 12 


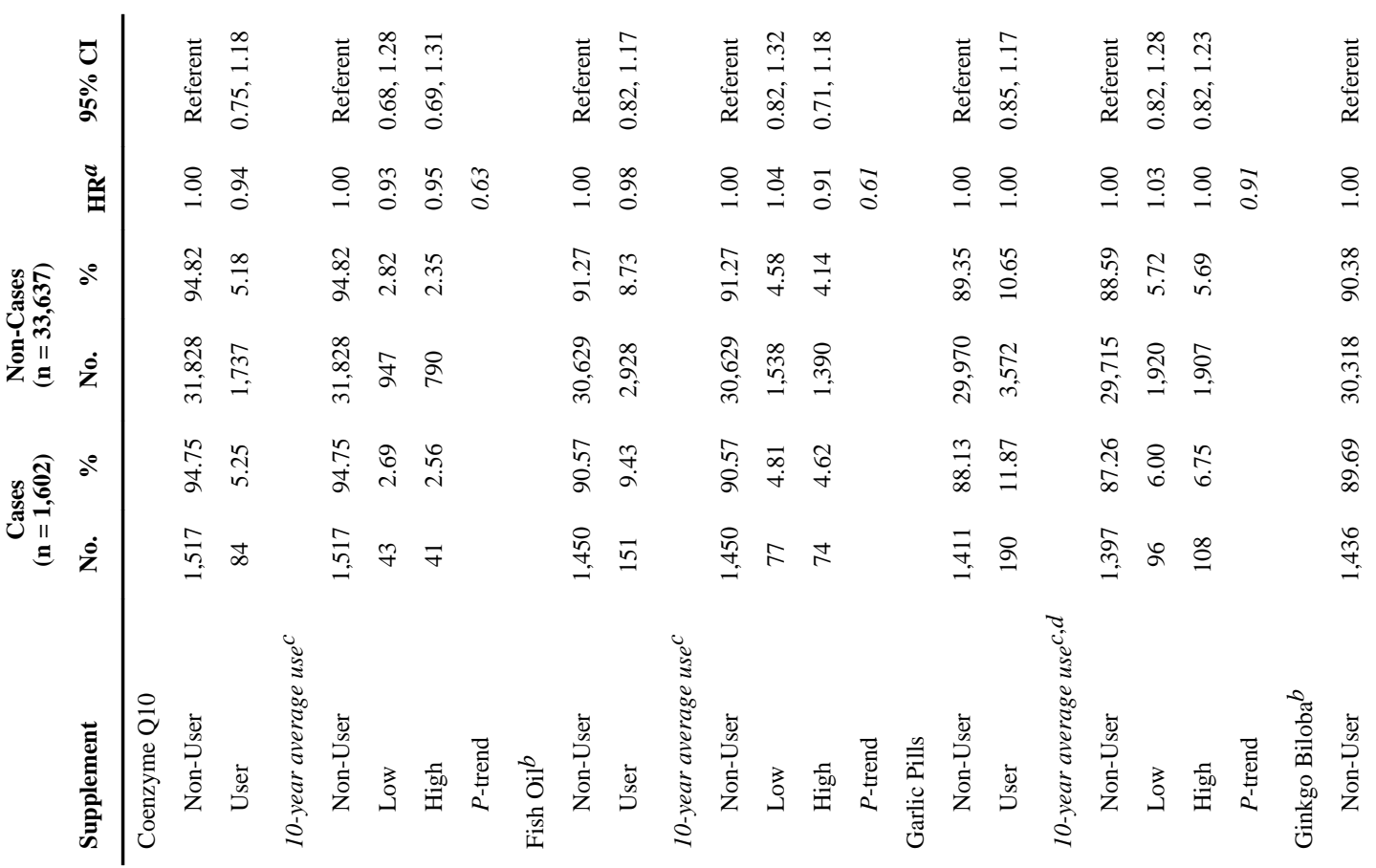




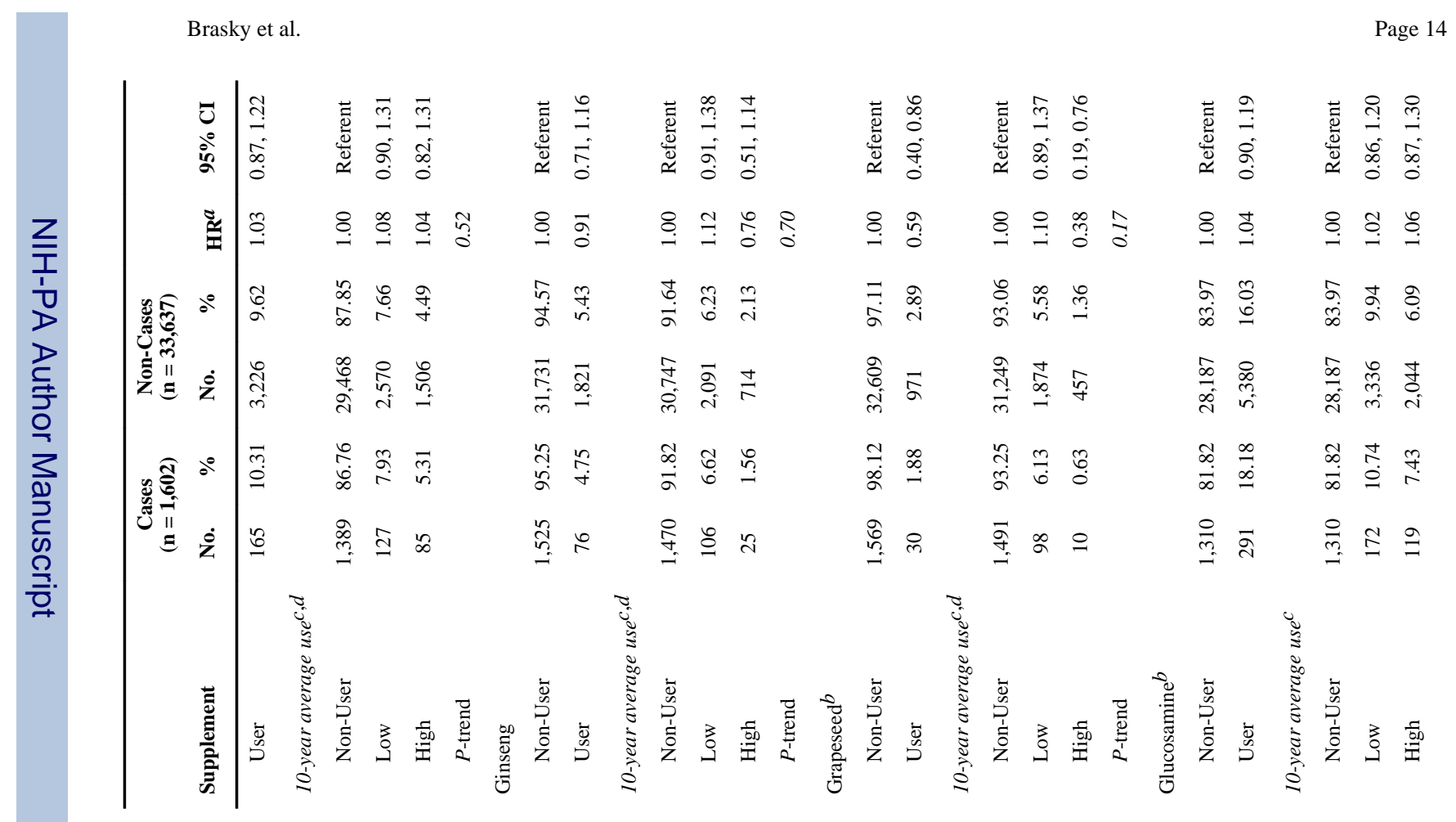




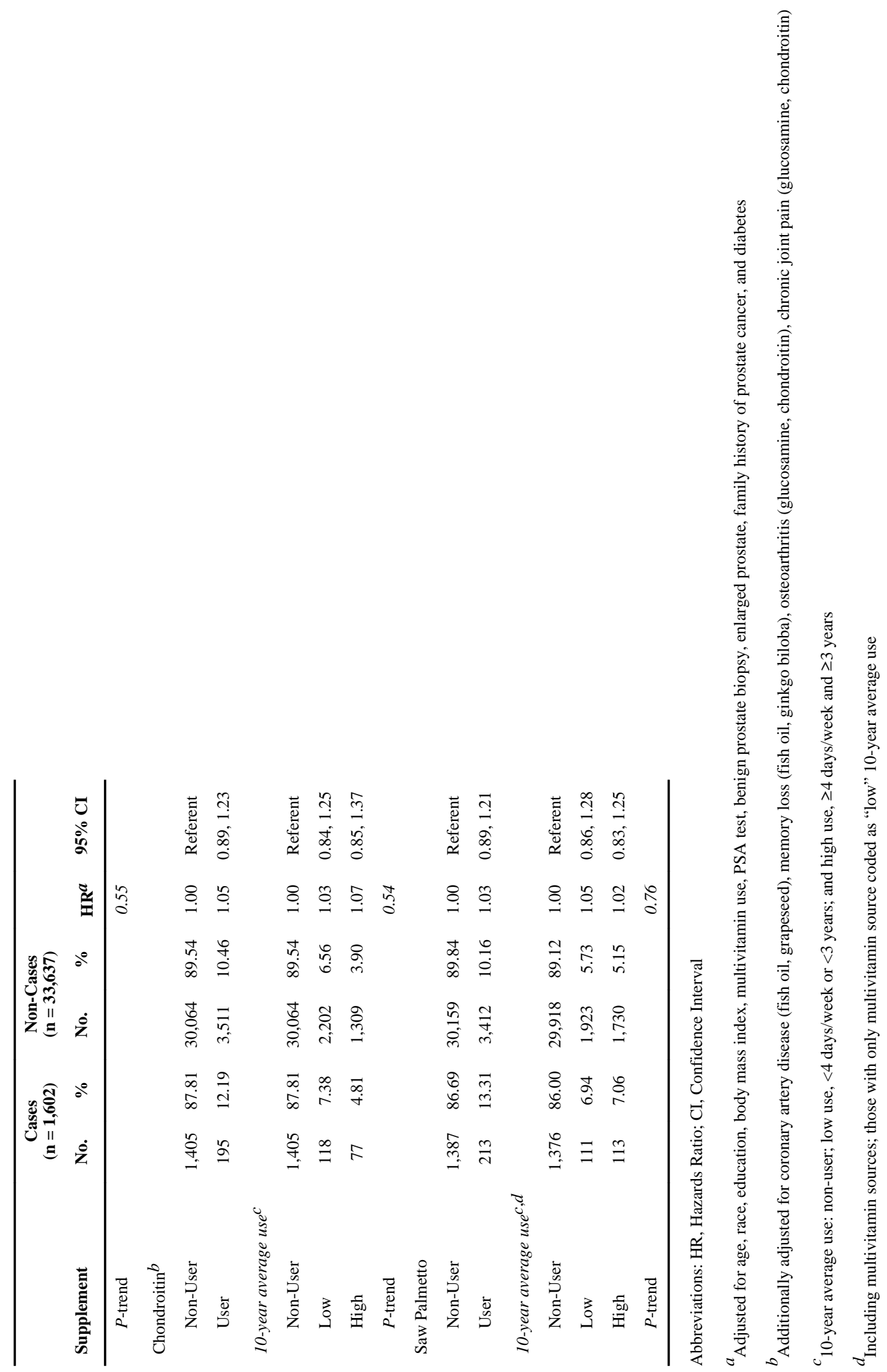




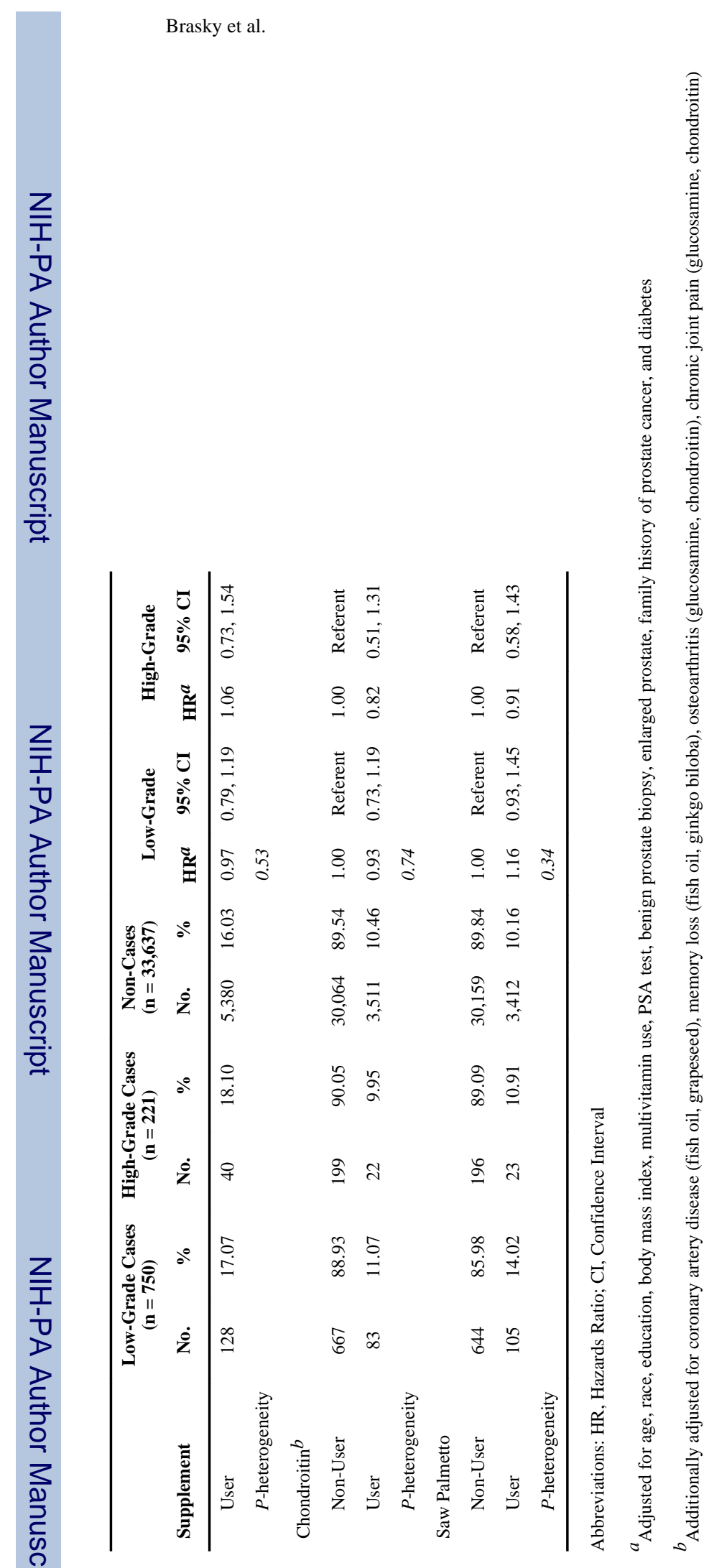

Nutr Cancer. Author manuscript; available in PMC 2012 May 1. 